\title{
Hybrid Energy Harvesting Scheme Using Piezoelectric and Thermoelectric Generators
}

\author{
Ali Mohammed Abdal-Kadhim ${ }^{1, *}$, Kok Swee Leong ${ }^{1}$ \\ ${ }^{1}$ Centre for Telecommunication Research and Innovation (CeTRI), Faculty of Electronic and Computer Engineering \\ (FKEKK), Universiti Teknikal Malaysia Melaka (UTeM), Hang Tuah Jaya, 76100 Durian Tunggal, Melaka, Malaysia
}

\author{
*Ali Mohammed Abdal-Kadhim
}

DOI: https://doi.org/10.30880/ijie.2019.11.01.003

Received 13 March 2018; Accepted 28 August 2018; Available online 30 April 2019

\begin{abstract}
This paper presents and evaluates the effectiveness of using a hybrid energy harvesting scheme consisting of AC and DC generators based on piezoelectric and Thermoelectric respectively, for powering a wireless sensor node. In comparison to conventional single harvesting mechanism, a hybrid scheme able to complement each other to ensure a more sustainable application. In this project, heat and vibration, which are ubiquitous from the ambient environment especially those in an oil and gas industries, are being explored, converted and integrated in the form of a hybrid topology in order to increase the chances of survivability of the wireless sensor node. The experimental result showed that charging time required to fully charge a $5 \mathrm{~V}, 15 \mathrm{mF}$ capacitor bank for parallel is $27 \mathrm{~s}$ while for series is $20 \mathrm{~s}$. It clearly show that piezoelectric and thermoelectric generators arranged in series topology is better compare to in parallel, in term of capacitor charging time.
\end{abstract}

Keywords: Hybrid energy harvesting, Wireless sensor node, Piezoelectric, Thermoelectric.

\section{Introduction}

The innovation of wireless sensor networks (WSNs) has been effectively utilized as a part of numerous applications such as environmental/earth monitoring, healthcare, industrial, and security in the most recent decade [1]. Since then WSN has drawn the industrial community attention due to their potential applications and commercial value. A typical WSN consists of a large number of micro, low-cost, low-power consumption and spatially distributed autonomous devices named "nodes" which combine sensors, control chip, communication module, and power supply module etcetera on a small board to cooperatively monitor physical or environmental conditions. The design and fabrication of these sensor nodes are confined to three kind of resources: (Energy, Memory, and Processing) [2]. The energy source of the sensor node is the most important and critical resource. Generally, sensor nodes power consumption is divided into three phases: sensing, data processing, and communication. Data communication phase has the highest power consumption rating among the other two phases in a typical sensor node [3]. Hence, researchers are working towards developing low-power radio modules and practicing local data processing in order to minimize the power consumption in the sensor nodes. The usual power source of the sensor nodes is the battery, which is troublesome and will limit the node lifetime and functionality. Periodic battery replacement/ maintenance is an uneconomical solution, however, it's unavoidable. Moreover, in some applications, it's impossible for the engineers to access the node after it has been installed. Subsequently, batteries constraints have become a serious issue that hinders the functionality of the WSNs overall.

In this respect and due to the batteries issues, recently, researchers and developers around the globe have been engaged in developing an energy-harvesting (also referred to as energy scavenging) techniques. Where the ultimate goal is to eliminate the battery usage and operate the sensor nodes from the ambient energy where the sensor node itself 
lies. All that effort from the researchers and developers has led to the introduction of many wireless sensor nodes prototypes based on energy harvesting approach. For instance, Liquan [4] has presented a wireless sensor node "Jennic JN5139" for industrial application powered by a commercial thermoelectric module TGM287-1.0-1.3 from Kryotherm, with DC-DC boost circuit based on LTC3108. Three stages battery-less boost converters for harvesting thermoelectricity using TEC1-12706, along with MPPT method are presented in [5]. It is suggested to be utilized in automobile applications for reusing the heat energy generated during fuel combustion. Another example can be found in [6], where suganti presented solar harvesting scheme to power up an "IRIS mote" wireless node with $3.3 \mathrm{~V}$ at $25 \mathrm{~mA}$ and $8 \mu \mathrm{A}$ for active and sleep mode respectively. The solar harvester was based on MCP0.8 solar panel, along with MPPT approach to achieve the maximum power. RF energy also considers a promising energy to be harvested since RF signals are widely available around us. Whereby, the author of [7] proposes an antenna design along with the rectifier circuit in order to harvest $2.4 \mathrm{GHz}-5.8 \mathrm{GHz}$ RF energy for wireless sensor node applications. Piezoelectric also has a great part in the energy harvesting area, where from our previous work [8] we had succeeded to power up a simple wireless sensor node from a piezoelectric cantilever excited via vibrator at $290 \mathrm{~Hz}$. Also we studied the effect of $\mathrm{g}$-level changing to the recovered power.

All the previously mentioned studies successfully eliminated the batteries usage by utilizing single harvester scheme within the system. However, single power source is not enough to make the sensor node system reliable, where the sensor node defiantly will become out of service in the absence of that ambient energy in case of single harvester scheme. Therefore, in this research paper did not only exclude the traditional power supply battery but present a hybrid energy harvesting scheme to recover both mechanical vibration and the heat energy by employing piezoelectric and thermoelectric technologies. By utilizing this hybrid scheme, it will overcome the absence of ambient energy issue. Moreover, it will increase the wireless sensor node reliability and availability.

\section{Batteries Versus Capacitors as Energy Storage Element}

Battery is considered the essential power supply for most wireless sensor nodes. Because battery recharging cycles are limited and they are unable to maintain the full charge for a long time even without use, thus, battery are considered the main constraint in the sensor nodes' lifespan, where battery service/replacement is crucial every few years. Although batteries take up to few years to be fully depleted, however, a periodic service/replacement is likely to be difficult, expensive, or even prohibitive in cases where there are dozens of millions of sensor nodes that are spatially deployed within a large-scale area. After substituting the traditional batteries with the supercapacitors along with the energy harvesting approach, a viable option that prolongs the wireless node lifespan will be obtained. Furthermore, the supercapacitors' features such as power density, low equivalent series resistance (ESR), lower leakage current, and etcetera [9] help to further grab the researchers' attention. It can be seen from Table 1 that the supercapacitors is able to provide about 500,000 times full charged cycles compared to 300-500 times in case of batteries. Besides, it can also work up to 20 years prior loss of $20 \%$ energy capacity and doubled its internal resistance, where it is the level of which half the original capacity is feasible for supercapacitors or traditional batteries at rated current. In general, supercapacitors have the ability to provide a continuous current higher than traditional batteries. For instance, Maxell350F supercapacitor is able to deliver more than $80 \mathrm{~A}$ of continuous current, thus when the wireless sensor node consumes lower than $8 \mathrm{~A}$ peak current, it leads to efficient utilization of most of the remaining capacity. It is estimated that supercapacitors take up to 20 years to lose $50 \%$ of its capacity. Fig. 1 illustrates the energy portion for the different kinds of energy storage that is previously reviewed [10][11].

Table 1 - Compares energy storage (batteries and supercapacitors) available for wireless sensor nodes applications [10].

\begin{tabular}{lcccc}
\hline & \multicolumn{2}{c}{ Rechargeable batteries } & \multicolumn{2}{c}{ Supercapacitors } \\
\hline & $\begin{array}{c}\text { Panasonic } \\
\text { HHR210AA/B } \\
\text { NiMH }\end{array}$ & $\begin{array}{c}\text { Panasonic } \\
\text { CGR17500 } \\
\text { Li-Ion }\end{array}$ & Maxwell BCAP350 & Maxwell PC10 \\
$\begin{array}{l}\text { Storage } \\
\text { type }\end{array}$ & 300 & 500 & 500000 & $10 \mathrm{~F}$ \\
$\begin{array}{l}\text { Charging } \\
\text { cycles } \\
\text { Capacity } \\
\text { (mAh) }\end{array}$ & 2000 & 830 & 243 & $\begin{array}{c}\text { Supercapacitor } \\
500000\end{array}$ \\
$\begin{array}{l}\text { Nominal } \\
\text { voltage (v) } \\
\text { Life time }\end{array}$ & 1.2 & 3.6 & 2.5 & 6.9 \\
\hline
\end{tabular}




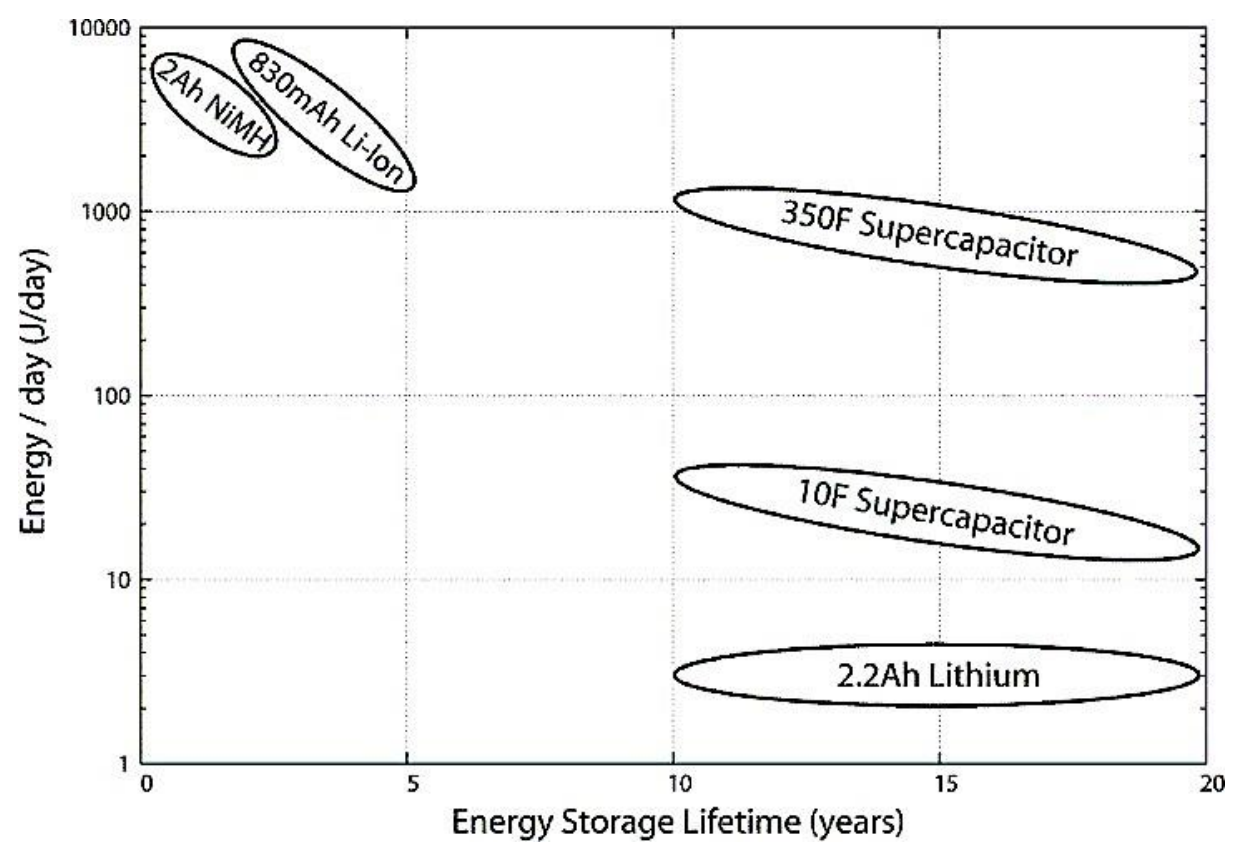

Fig. 1 - Maximum energy portions for energy storages showed in Table 1 [10].

\section{Energy Harvesting System Design and Evaluation}

\subsection{Piezoelectric Based Vibration Energy Harvester}

Vibration energy harvesting is the concept of converting the kinetic energy inherent in vibrations to electricity, where vibration energy is available in abundance around us especially in the industry. For that reason many researchers and developers around the globe have paid high attention to recover that wasted energy into a useful electricity [12]. Traditionally, the vibration is being disposed into shock absorbers or into the ground. To recover that wasted energy, a piezoelectric cantilever beam with a tip mass is utilized. When this transducer is being deformed via the vibration it will produce an alternating electrical charges on its terminals. Since the output of the piezoelectric is in alternating current form, thus, a rectifier and filtering circuits are required.

Since the piezoelectric cantilever will be actuated using the vibration energy generated via industrial machinery, therefore studying the vibration components is essential. Fauzi et al [13] have studied the vibration generated in the household devices, they found out plenty of them are able to produce a vibration in range of $0-100 \mathrm{~Hz}$ with acceleration of less than $0.2 \mathrm{~g}$. However, the authors have spotted that a small number of the household devices were able to produce higher than $0.2 \mathrm{~g}$ of acceleration level in case of the blender, standing fan, and grinding machine. Arko [14] studied the behavior of a rotary machine, and they stated that the g-level of the rotary machine in a balance condition is about $2.5 \mathrm{~g}$, and the unbalance condition could lead to an increase the machine vibration displacements up to $3.5 \mathrm{~g}$. Steven and others [15] stated in their literature review about the transportation shock and vibration that a cargo weight ranged from no-load to 15 tons, it generates a vibration of 0.001-1.9 KHz with g-level of 1.6-0.4g respectively. James [16] presented a maintenance program for an industrial machinery, where they come out with a recommended maintenance alert levels chart according to the g-level 0.1-7g and the rotational speed 1-10000 RPM. Moreover, they showed a real example of a machine turning at 10RPM, the normal g-level of the normal operation is below 0.1g, and the g-level increased dramatically within the operation time due to a ware out until reaching above $0.7 \mathrm{~g}$. Table 2 concludes the above reviews.

Table 2 - The conclusion of vibrations' frequencies and the acceleration level literature.

\begin{tabular}{lcc}
\hline \multicolumn{1}{c}{ Studies } & Frequency $(\mathbf{K H z})$ & Acceleration level (g) \\
\hline Fauzi et al. [13] & $0-0.1$ & 0.2 \\
Arko et al. [14] & $0.001-1$ & $0.25-3.5$ \\
Steven et al. [15] & $0.001-1.9$ & $0.4-1.6$ \\
James et al. [16] & $1-10$ & $0.1-7$
\end{tabular}


As a conclusion the mechanical vibration is widely available around us from both household devices and industrial machineries. It is available with frequency of $0.001-1.9 \mathrm{KHz}$ with acceleration level of $0.2-3.5 \mathrm{~g}$. Even though the measured frequency is quite varied however, it is an easy matter to tweak out the piezoelectric resonant frequency by the mean of shortening the piezoelectric length or applied proof of mass to match the available frequency. For vibration energy harvesting proof of concept, a rectangular piezoelectric cantilever $70 \mathrm{X} 32 \mathrm{X} 0.55 \mathrm{~mm}$ manufactured by Piezo System mounted on a vertical shaker. The shaker applies a vibration with frequency of $69 \mathrm{~Hz}$ and acceleration level of $0.5 \mathrm{~g}$ which matches the resonant frequency of the used cantilever. An alternating voltage of $17 \mathrm{~V}$ pk-pk is measured at the piezoelectric terminal while it was vibrating. Fullwave bridge rectifier is designed based on four schottky barrier diodes to rectify the piezoelectric output along with $47 \mu \mathrm{F}$ smoothing capacitor. These Schottky barrier diodes as shown in the schematics in Fig. 2 are chosen due to the high current handling capability and low forward voltage performance. A capacitor bank $15 \mathrm{mF}$ is used to evaluate the piezoelectric harvester by measuring the charging time from 0 to $5 \mathrm{~V}$. Where it takes about 1 hour to fully charge the capacitor bank up to $5 \mathrm{~V}$.

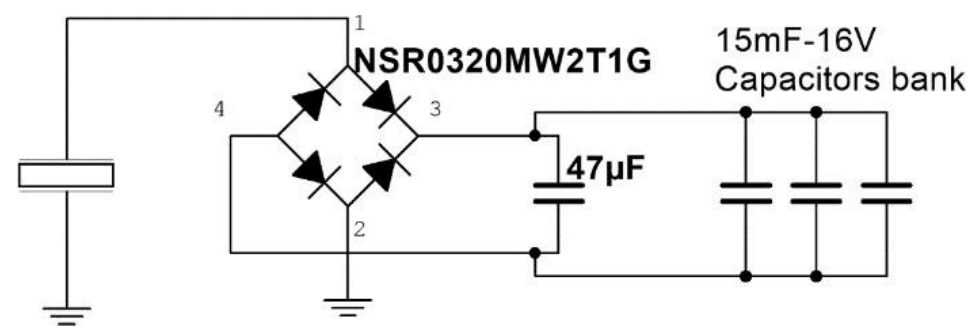

Fig. 2 - Schematic of the rectifier and filter circuit for the piezoelectric transducer.

\subsection{Thermoelectric Based Heat Energy Harvester}

A thermoelectric generator TEG is being utilized as thermal energy harvester, where TEG is able to recover the wasted heat energy that is emitted from various devices into useful electrical energy. TEG is utilizing Seebeck effect [17], whereby, an electrical energy will be generated on its terminals whenever there are temperature differences on its surfaces. Due to the TEG's reliability, compactness, lightweight, and no moving parts required, it has become a preferable choice for the researchers among the other energy harvesting technologies. Based on the TEG functionality principles, a mini survey was conducted to investigate various low-level heat sources that can be categorized as household electrical appliances in our research [18]. This survey was targeted at the low-level of heat emission(less than $150{ }^{\circ} \mathrm{C}$ ). These items considered good heat sources for the application of energy harvesting since they operate almost $24 / 7$.

From Fig. 3 it can be clearly observed that the tested devices are generally emitting from $40^{\circ} \mathrm{C}$ in case of laptop charger up to $130^{\circ} \mathrm{C}$ in case of steam pressure cooker during their operating time. Since the ambient room temperature was measured at about $28^{\circ} \mathrm{C}$. Therefore, the delta of temperature for every tested item in the figure can be obtained via " $\Delta T=$ Heat Emitted-Room Temperature", which starts from $\Delta \mathrm{T}=18^{\circ} \mathrm{C}$ up to $\Delta \mathrm{T}=100^{\circ} \mathrm{C}$.

Since the thermoelectric cooler Peltier module can be utilized as a thermal energy harvester as good as the TEG module in low-temperature gradients below $100^{\circ} \mathrm{C}$, adding on a single TEG unit is 5 times more costly than a Peltier unit [19]. Therefore, and in order to cut down the harvester manufacturing cost, a Peltier module has been chosen instead of TEG module to conduct this research experiment. An evaluation experiment is conducted in order to characterize the TEG module before it is being used in the harvesting system. The characterization was done by exposing the TEG module to different temperature gradients using heating element and measuring the recovered voltages. Moreover, it's been proven that by cascading more of the TEGs modules electrically connected in series it doesn't have much effect on the $\mathrm{V}$-out compared to an increase the $\Delta \mathrm{T}$. Where at $\Delta \mathrm{T}=60^{\circ} \mathrm{C}$ the $\mathrm{V}$-out will be increased by $0.5 \mathrm{~V}$ only with every stacked TEG [18]. Thus, two TEG modules only from Laird [HT8, 12 Laird UM08] are stacked on each other and electrically connected in series are used in this research. These tow modules are able to recover $0.5 \mathrm{~V}$ at $\Delta \mathrm{T}$ of $10^{\circ} \mathrm{C}$ then it increased with direct proportional manner with $\Delta \mathrm{T}$ as illustrated in Fig. 4.

According to the Fig. 3, most of the measured devices emitted about $70^{\circ} \mathrm{C}$ of heat to the environment during their operation, and the measured room temperature was about $28^{\circ} \mathrm{C}$. Therefore, about $40^{\circ} \mathrm{C}$ as a temperature gradient $\Delta \mathrm{T}$ on the TEG surfaces will be obtained. This point of temperature is chosen for the harvester evaluation. At $40^{\circ} \mathrm{C} \Delta \mathrm{T}$, TEGs modules are able to recover about $2 \mathrm{~V}$ as clear in the Fig. 4. Thus, a DC-DC boost converter is needed to boost the recovered voltage to 5V. DC-DC boost converter is designed based on TPS61041. This IC is chosen due to its availability, small size, low-cost, and also it is only required few passive components to operate. Fig. 5 shows the schematics of the proposed system. The TPS61041 is capable to operate from low voltages as $1.8 \mathrm{~V}$ and boost the output with adjustable range up to $28 \mathrm{~V}$. Therefore, a voltage divider of (R1 and R2) is obtained to set the booster output to $5 \mathrm{~V}$. A capacitor bank of $15 \mathrm{mF}$ is again used to evaluate the thermoelectric harvester by measuring the charging time from 0 to $5 \mathrm{~V}$. This harvester is incredibly fast where it takes about 30 s to fully charge the capacitor bank up to $5 \mathrm{~V}$, 
which is about 0.0083 in an hour. This fast charging time is due to the high current produced via the thermal harvester compared to the piezoelectric.

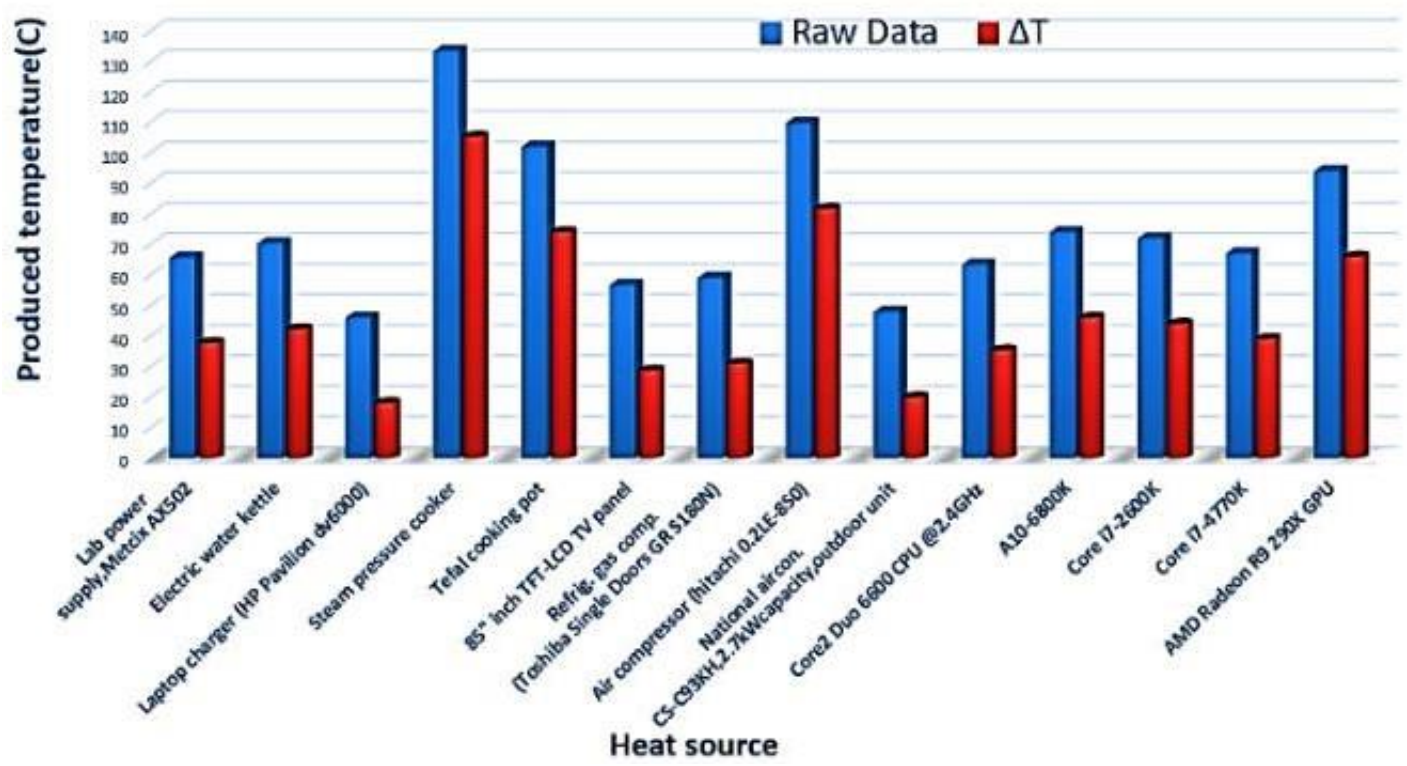

Fig. 3 - Low-level heat sources survey [18].

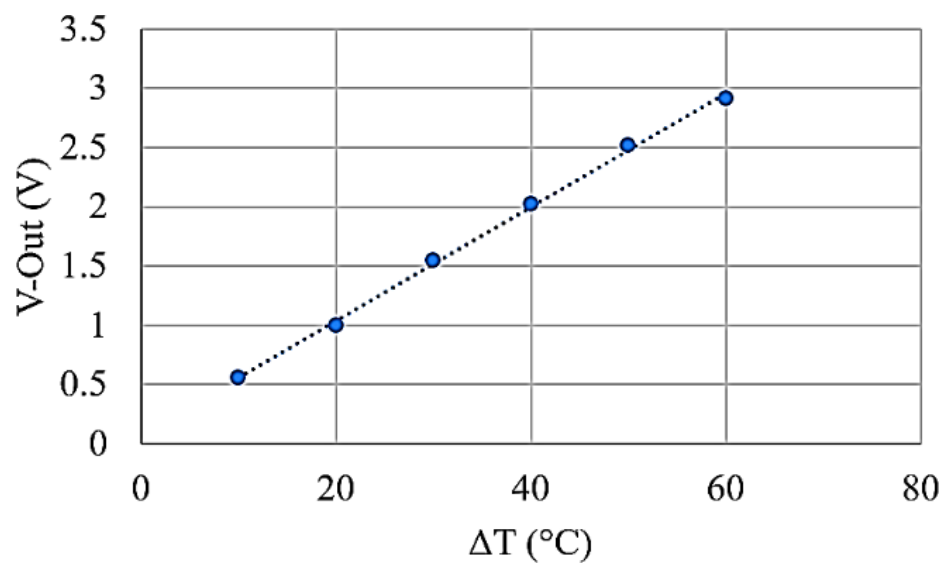

Fig. 4 - The recovered voltage from two TEC at different $\Delta$ T gradient.

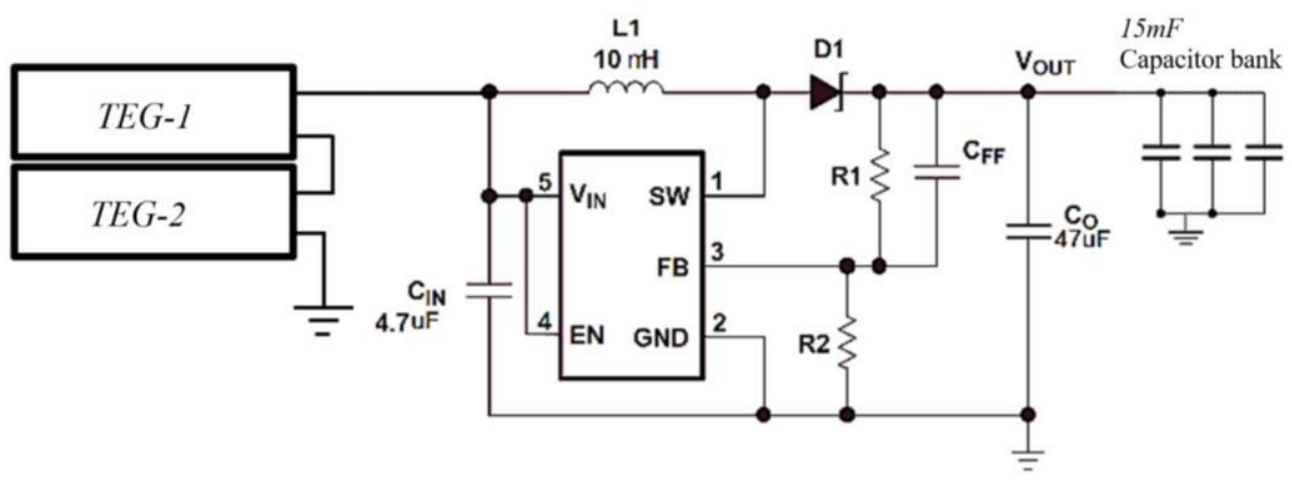

Fig. 5 - TECs harvester and the DC-DC boost converter schematic. 


\section{Hybrid Energy Harvesting System Design and Evaluation}

Hybrid energy harvesting is a process of merging more than one energy harvester to serve a single system [20]. Utilizing this scheme can overcome the single harvester drawbacks like weakness, intermittence, and inconsistency, also, it will guarantee the electrical energy availability for the system even in the lack of one of the other ambient energy sources. Furthermore, by merging more than one harvester more power can be achieved and system reliability and efficiency will be increased accordingly. The functionality of the hybrid energy harvester fully relies on each subsystem circuit design, and also depends on the connection topology.

A slight reduction in the charging time of the $15 \mathrm{mF}$ capacitor bank can be noticed when connecting the thermoelectric harvester circuit in parallel with the piezoelectric harvester circuit, Fig. 6 illustrates the parallel connection of the hybrid harvester. This reduction in the charging time is due to the fact that the overall hybrid harvester current will be increased according to the parallel topology. Whereby, $I_{\text {hybrid }}=I_{T E G}+I_{P I Z O}$. Since the piezoelectric transducer produces very small amount of current compared to the thermoelectric, the total current is slightly increased and so does the charging power. The new charging time for the parallel harvester was recorded to be about 27s. Which is lower than the thermoelectric harvester alone, and the piezoelectric harvester alone.

Even though there is not much improvement in the charging time for the capacitor bank in the parallel hybrid harvester topology. However, there is a drastic improvement when connecting the thermoelectric harvester in series with the piezoelectric harvester, as shown in Fig. 7. The overall voltage of the hybrid harvester in the series topology will be combining both thermoelectric and piezoelectric harvesters' voltages. Whereby, $V_{\text {hybrid }}=V_{T E G}+V_{P I Z O}$. Moreover, both of thermoelectric and the piezoelectric harvesters are able to produce $5 \mathrm{~V}$, therefore will lead to an increase in the total hybrid voltage and hence increasing the charging power, where $P=I^{*} V$. In this context the new charging time for the series harvester topology was recorded about 2s. Which is lower than the thermoelectric harvester alone, piezoelectric harvester alone, even lower than the hybrid parallel topology.

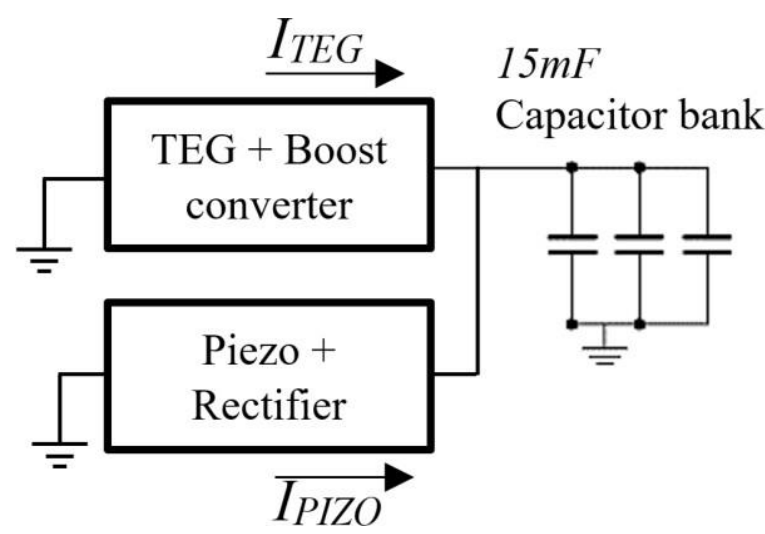

Fig. 6 - Schematics of the hybrid energy harvester (parallel topology).

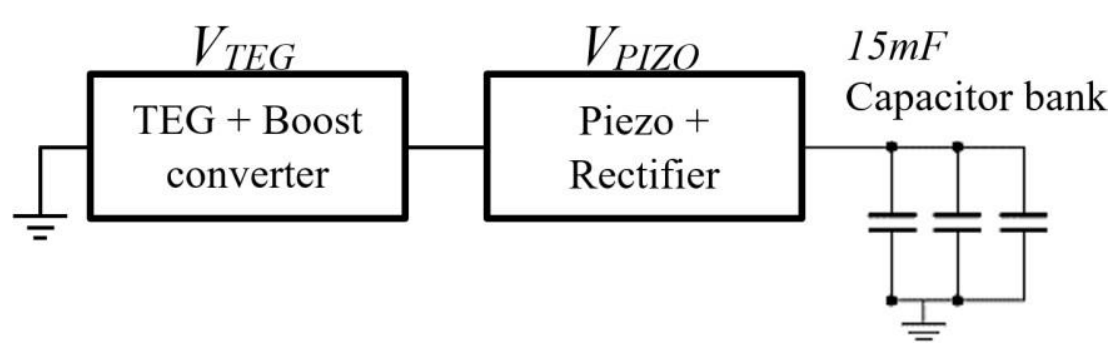

Fig. 7 - Schematics of the hybrid energy harvester (series topology).

\section{Hybrid Energy Harvester Evaluation in Case of a Missing Resource}

As previously mentioned, and as it is obvious that the hybrid energy harvester scheme has recovered more than one kind of the ambient energy, which is considered a good aspect to improve the system reliability and efficiency. However, it is very difficult to guarantee that both of the ambient energy sources (this research focusing on heat and vibration) are available in the environment at the same time. Therefore, in this phase of this research the hybrid harvester charging time in case of one of the ambient energy sources is missing will be studied and evaluated. The first evaluation setup is connecting the harvesters circuits in series and activating the piezoelectric harvester only. In this 
scenario, the hybrid harvester requires 1 hour to fully charge the same $15 \mathrm{mF}$ capacitor bank to $5 \mathrm{~V}$. The long time is due to the lack of heat which leads to disabling the thermoelectric harvester. Next scenario, is to keep the harvesters connected in series but this time activating the thermoelectric harvester only, which in turn took about 30 s to charge the capacitor bank.

The second evaluation setup is connecting the harvesters circuits in parallel and again activating only one harvester at a time. First scenario, is by activating piezoelectric harvester only and trying to charge up the capacitor bank again. It is expected to take 1hour only to charge the load, however, it spends 30 minutes extra over the 1hour until the load is fully charged. This extra time is because the charging power is reduced. Power charging is reduced because the harvesters are connected in parallel and since the thermoelectric harvester is not activated and doesn't participant in the charging power, but, it acts as an extra load in the system due to the voltage divider resistors (R1, R2) in the thermoelectric boost converter circuit as shown in Fig. 5. Last scenario in this setup is activating the thermoelectric harvester only. Again in this case it requires only 30s to charge the capacitor bank. Table 3, and Table 4 conclude the charging time for all the previous scenarios and states.

Table 3 - Charging time for the hybrid harvester in a series topology

\begin{tabular}{|c|l|l|l|}
\hline \multicolumn{3}{|c|}{ Series topology } \\
\hline Technology & \multicolumn{3}{|c|}{ TEG } \\
\hline PIZO & state & on & off \\
\hline & on & 20 s & $1 \mathrm{~h}$ \\
\hline & off & $30 \mathrm{~s}$ & null \\
\hline
\end{tabular}

Table 4 - Charging time for the hybrid harvester in a parallel topology

\begin{tabular}{|c|l|l|l|}
\hline \multicolumn{4}{|c|}{ Parallel topology } \\
\hline Technology & \multicolumn{3}{|c|}{ TEG } \\
\hline PIZO & state & on & off \\
& on & $27 \mathrm{~s}$ & $1.5 \mathrm{~h}$ \\
\hline & off & $30 \mathrm{~s}$ & null \\
\hline
\end{tabular}

\section{Conclusion}

This research paper experimentally evaluate the performance of a hybrid energy harvester compared to a single energy harvester. The evaluation was based on the time required to fully charge a capacitor bank of $15 \mathrm{mF} u p$ to $5 \mathrm{~V}$. The hybrid energy harvester was based on thermoelectric harvester and piezoelectric harvesters. Fullwave bridge rectifier based on schottky barrier diodes are used to rectify the piezoelectric output along with a smoothing capacitor. DC-DC boost converter is designed based on TPS61041 used to boost up the thermoelectric output to 5V.Both of these harvesters were tested as a hybrid energy harvester by connecting them in parallel and series topologies. The hybrid energy harvester is able to overcome the single harvester drawbacks like weakness, intermittence and inconsistency. Moreover, it will guarantee that the electrical energy will be always be available for the system even in case of the lack of one of the other sources. Furthermore, by merging more than one harvester, more power can be achieved and system reliability and efficiency will be increased accordingly. The experimental measurements show that there is a high improvement in the charging time by merging more than one harvester. However, there is a slight difference between series and parallel topology for the same hybrid scheme. Whereby, it can be concluded from the result that the series topology is better than the parallel topology for its shorter charging time.

\section{Acknowledgement}

The authors would like to thank the Malaysian government for its research grant of PRGS/1/2016/TK10/FKEKKCETRI/02/T00016 and the Facility support by Advanced Sensors and Embedded Control System (ASECs), Centre for Telecommunication Research and Innovation (CeTRI), Universiti Teknikal Malaysia Melaka (UTeM).

\section{References}

[1] Yick, J., Mukherjee, B., and Ghosal, D. Wireless sensor network survey. Computer Networks, Volume 52, (2008), pp. 2292-2330.

[2] Vehbi, C., Gungor, Gerhard, P., and Hancke, Industrial Wireless Sensor Networks: Challenges, Design Principles, and Technical Approaches. IEEE Transactions on Industrial Electronics, Volume 56, (2009), pp. 4258 - 4265.

[3] Akyildiz, I.F., Melodia, T., and Chowdhury, K. A survey on wireless multimedia sensor networks. Comput. Netw., Volume 51, (2007), pp. 921-960. 
[4] Liqun, H., and Shudong, T. A Preliminary Study of Thermal Energy Harvesting for Industrial Wireless Sensor Networks. Tenth International Conference on Sensing Technology, (2016), pp. 1-5.

[5] Nisha, K.S., and Mini, V.P. Battery-less Boost Converter for Thermal Energy Harvesting System. International Conference on Control, Communication \& Computing India (ICCC), (2015), pp. 19-21.

[6] Suganti, S., Micheal, D., Balbir, S.M.S., Patrick, S., and Lo, H.H. An MPPT Micro Solar Energy Harvester for Wireless Sensor Networks. IEEE 13th International Colloquium on Signal Processing \& its Applications, (2017), pp. 84-89.

[7] Saad, B.A., and Sanjida, M. Multiple-Band Antenna Coupled Rectifier Circuit for Ambient RF Energy Harvesting for WSN. 3rd International Conference on Informatics, Electronics \& Vision, (2014), pp. 1-4.

[8] Ali, M.A., Kok, S.L., Norizan, B.M. Application of Piezoelectric Energy Harvesting in Powering Radio Frequency (RF) Module. Journal of Telecommunication, Electronic and Computer Engineering, Volume 8, (2016), pp. 77-79.

[9] Maxwell Technologies, "BCAP0350 Datasheet," Tech. Rep., August. 2018 [Online]. Available: http://www.maxwell.com.

[10] Farhan, I.S., and Pai, H.C. Efficient Charging of Supercapacitors for Extended Lifetime of Wireless Sensor Nodes. IEEE Transactions on Power Electronics, Volume 23, (2008), pp. 1526-1536.

[11] Lu, W., Yuzhen, H., Xiao, F., Junwen, Z., Pengfei, Q., and Bo, W. Metal-organic frameworks for energy storage: Batteries and supercapacitors. Coordination Chemistry Reviews, Volume 307, (2016), pp. 361-381.

[12] Robert, K., Matthew, M., Richard, G., and Burak, A. Low Frequency and Broadband Vibration Energy Harvesting Using Base Mounted Piezoelectric Transducers. IEEE Transactions on Ultrasonics, Ferroelectrics, and Frequency Control, Volume 64, (2017), pp. 1735 - 1743.

[13] Mohd, F.B., and Kok, S.L. Investigation of useful ambient vibration sources for the application of energy harvesting. IEEE Student Conference on Research and Development, (2011), pp. 391-396.

[14] Arko, D., Arsi, A., Rusman, R., and Erikson, S. Monitoring Vibration Of A Model Of Rotating Machine. Journal of Mechatronics, Electrical Power, and Vehicular Technology, Volume 02, (2011), pp 51-56.

[15] Steven, J.M., Erik, A.L., and Steven, B.R. Transportation Shock and Vibration Literature Review. U.S. Department of Energy Used Fuel Disposition Campaign, FCRD-UFD-2013-000169, PNNL-22514, (2013), pp. 164.

[16] James, C.R., and Stephen, A. Two Parameter Predictive Maintenance Program. Sensors for Machinery Health Monitoring, (2013), pp. 1-19.

[17] Simone, D., Marco, F., Vittorio, F., Michele, G., Daniele, M., and Andrea, T. Characterization of Thermoelectric Modules for Powering Autonomous Sensors. IEEE Transactions on Instrumentation and Measurement, Volume 58, (2009), pp. 99-107.

[18] Ali, M.A., and Kok, S.L. Characterizations of thermoelectric for energy harvesting on low-level heat sources. Proceedings of Mechanical Engineering Research Day, (2017), pp. 164-165.

[19] Marco, N., and Georg, F. Thermoelectric Power Generation: Peltier Element versus Thermoelectric Generator. 42nd Annual Conference of the IEEE Industrial Electronics Society, (2016), pp. 1-6.

[20] Ranjit, S.S.S., Maysam, A., and Wamadeva, B. Low Voltage Hybrid Renewable Energy System Management for Energy Storages Charging-Discharging. IEEE International Energy Conference (ENERGYCON), (2016), pp. 1-6. 